\title{
Is host crop identity a stronger determinant than cover cropping for arbuscular mycorrhizal fungal communities colonizing maize and soybean roots?
}

\author{
Masao Higo ${ }^{\text {Corresp.. }}{ }^{1}$, Yuya Tatewaki ${ }^{1}$, Kento Gunji ${ }^{1}$, Akari Kaseda ${ }^{1}$ ， Katsunori Isobe ${ }^{1}$ \\ 1 Department of Agricultural Bioscience, College of Bioresource Sciences, Nihon University, Fujisawa, Kanagawa, Japan \\ Corresponding Author: Masao Higo \\ Email address: higo.masao@nihon-u.ac.jp
}

Background: Understanding the role of communities of arbuscular mycorrhizal fungi (AMF) in agricultural systems is imperative for enhancing crop production. The key variables influencing change in AMF communities are the type of cover crop species or the type of subsequent host crop species. However, how maize and soybean performance is related to the diversity of AMF communities in cover cropping systems remains unclear. We therefore investigated which cover cropping or host identity is the most important factor in shaping AMF community structure in subsequent crop roots using an Illumina Miseq platform amplicon sequencing.

Methods: In this study, we established three cover crop systems (Italian ryegrass, hairy vetch, and brown mustard) or bare fallow prior to planting maize and soybean as cash crops. After cover cropping, we divided the cover crop experimental plots into two subsequent crop plots (maize and soybean) to understand which cover cropping or host crop identity is an important factor for determining the AMF communities and diversity both in maize and soybeans.

Results: We found that most of the operational taxonomic units (OTUs) in root samples were common in both maize and soybean, and the proportion of common generalists in this experiment for maize and soybean roots was $79.5 \%$ according to the multinomial species classification method (CLAM test). The proportion of OTUs specifically detected in only maize and soybean was $9.6 \%$ and $10.8 \%$, respectively. Additionally, the cover cropping noticeably altered the AMF community structure in the maize and soybean roots. However, the differentiation of AMF communities between maize and soybean was not significantly different.

Discussion: Our results suggest cover cropping prior to planting maize and soybean may be a strong factor for shaping AMF community structure in subsequent maize and soybean roots rather than two host crop identities. Additionally, we could not determine the suitable rotational combination for cover crops and subsequent maize and soybean crops to improve the diversity of the AMF communities in their roots. However, our findings may have implications for understanding suitable rotational combinations between cover crops and subsequent cash crops and further research should investigate in-depth the benefit of AMF on cash crop performances in cover crop rotational systems. 
1 Title: Is host crop identity a stronger determinant than cover cropping for arbuscular mycorrhizal

2 fungal communities colonizing maize and soybean roots?

3

4 Masao Higo $^{1}$, Yuya Tatewaki ${ }^{1}$, Kento Gunji ${ }^{1}$, Akari Kaseda ${ }^{1}$, Katsunori Isobe ${ }^{1}$ 5

6 1) Department of Agricultural Bioscience, College of Bioresource Sciences, Nihon University, $7 \quad 1866$ Kameino, Fujisawa, Kanagawa 252-0880, Japan

9 Corresponding author: Masao Higo

10 Tel: +81-466-84-3502

11 Fax: +81-466-84-3525

12 E-mail: higo.masao@,nihon-u.ac.jp

\section{Abstract}

15 Background: Understanding the role of communities of arbuscular mycorrhizal fungi (AMF) in agricultural systems is imperative for enhancing crop production. The key variables influencing change in AMF communities are the type of cover crop species or the type of subsequent host crop species. However, how maize and soybean performance is related to the diversity of AMF communities in cover cropping systems remains unclear. We therefore investigated which cover cropping or host identity is the most important factor in shaping AMF community structure in subsequent crop roots using an Illumina Miseq platform amplicon sequencing. Methods: In this study, we established three cover crop systems (Italian ryegrass, hairy vetch, and brown mustard) or bare fallow prior to planting maize and soybean as cash crops. After cover cropping, we divided the cover crop experimental plots into two subsequent crop plots (maize and soybean) to understand which cover cropping or host crop identity is an important factor for determining the AMF communities and diversity both in maize and soybeans.

27 Results: We found that most of the operational taxonomic units (OTUs) in root samples were common in both maize and soybean, and the proportion of common generalists in this 
experiment for maize and soybean roots was $79.5 \%$ according to the multinomial species classification method (CLAM test). The proportion of OTUs specifically detected in only maize and soybean was $9.6 \%$ and $10.8 \%$, respectively. Additionally, the cover cropping noticeably altered the AMF community structure in the maize and soybean roots. However, the differentiation of AMF communities between maize and soybean was not significantly different.

Discussion: Our results suggest cover cropping prior to planting maize and soybean may be a strong factor for shaping AMF community structure in subsequent maize and soybean roots rather than two host crop identities. Additionally, we could not determine the suitable rotational combination for cover crops and subsequent maize and soybean crops to improve the diversity of the AMF communities in their roots. However, our findings may have implications for understanding suitable rotational combinations between cover crops and subsequent cash crops and further research should investigate in-depth the benefit of AMF on cash crop performances in cover crop rotational systems.

\section{Introduction}

Growing cover crops can be an effective technique in crop rotations to enhance soil health and suppress weed populations (Snapp et al., 2005; Clark, 2008). Cover crops can cover fallow periods between cash crops that may be vulnerable to weed establishment or erosion. Shortseason cover crops are also utilized and overwintered (live until spring) in temperate regions to reduce soil erosion, increase soil organic matter (Snapp et al., 2005; García-González et al., 2018), and enhance the biomass of plant growth-promoting microorganisms, such as phosphate solubilizing fungi and arbuscular mycorrhizal fungi (AMF) (Lehman et al., 2012; Higo et al., 2013; Karasawa \& Takahashi, 2015; García-González et al., 2016).

It is well known that AMF can improve host plant phosphorus $(\mathrm{P})$ uptake and growth performance (Smith \& Read, 2008). These nutritional benefits of AMF can be enhanced through appropriate agricultural management (Gosling et al., 2006; Kahiluoto et al., 2012; Ryan \& Graham, 2018). Indeed, many previous studies have indicated that AMF benefits agricultural 
57 AMF hyphal abundance in soil during early growth to enhance P uptake as well as maize and soybean yield (Gavito \& Miller, 1998; Isobe et al., 2014). Additionally, agricultural practices may positively or negatively impact AMF taxonomic and functional community composition (Ohsowski et al., 2014; Xiang et al., 2016; Cofré et al., 2017; Xu et al., 2017; Zhao et al., 2017; Berruti et al., 2018; García de León et al., 2018; Higo et al., 2018b). Indeed, intensive agricultural practices, such as tillage, mono-cropping, seasonal fallow periods, and inorganic nutrient application, reduce both AMF populations and AMF benefits for field crops (Lehman et al., 2012; Higo et al., 2018a). On the contrary, adding cover crops during the winter period is also an effective technique in increasing indigenous AMF abundance in soil for following crops (Higo et al., 2015a). Thus, the introduction of cover crops, such as ryegrass (Lolium multiflorum), wheat (Triticum aestivum), mustards and oilseed rape (Brassicaceae) or leguminous crops, including hairy vetch (Vicia villosa Roth.) and clovers (Trifolium), in crop rotations in temperate agricultural systems is essential to reduce seasonal fallow and thus provides many benefits for subsequent crops and soil fertility (Karasawa \& Takahashi, 2015; Higo et al., 2018b). Given these facts regarding AMF in cover crop rotational systems, it is important to understand which agricultural management, such as cover crop species and crop rotation, positively or negatively impacts individual AMF taxa and community structures in roots and soil.

However, what remains poorly understood and unclear is which factor, such as cover cropping or host crop identity, is driving increases in cash crop performance and AMF diversity. Little is also known about how cover cropping and host identity are linked to the diversity of AMF community structure, and the effectiveness of AMF in cover crop rotational systems to improve the robustness and reliability of agricultural management. Additionally, the best combination of cover crops and subsequent cash crops (maize and soybean) in rotations to increase the diversity or to alter the structure of AMF communities remains unknown. Thus, the goal of this research was to determine 1) which cover cropping or host identity is the most important factor in shaping AMF community structure in subsequent crop roots, and 2) how cover cropping and host identity alter the belowground communities of AMF in two different types of subsequent maize and soybean crops. 
86 Materials and methods

\section{Experimental design}

88 A field experiment of cover crop rotation was established at Nihon University, in Kanagawa, 89 Japan $\left(35^{\circ} 22^{\prime} \mathrm{N} 139^{\circ} 27^{\prime} \mathrm{E}\right)$. The soil at the field site is classified as a volcanic ash soil 90 (Allophonic andosol). In this study, we examined the impact of cover cropping and host crop 91 type on the diversity of AMF communities colonizing roots of subsequent crops. We established 92 cover cropping treatments in rotation with maize (Zea mays L., cv: Snow Dent 125 Wakaba) or soybean (Glycine max (L.) Merr., cv: Enrei). Three cover crop treatments including Italian ryegrass (Lolium multiflorum Lam., cv: Akatsuki), hairy vetch (Vicia villosa Roth., cv: Mamekko), and brown mustard (Brassica juncea (L.) Czern \& Coss., cv: Karajin) or bare fallow was used to cover the soil surface during winter and the fallow period in annual cropping systems in a temperate region of Japan. There were three replicate plots per treatment arranged in a randomized complete block design. Each plot had an area of $9 \mathrm{~m}^{2}(3 \mathrm{~m} \times 3 \mathrm{~m})$. The Italian ryegrass, hairy vetch, and brown mustard were sown in rows, spaced $30 \mathrm{~cm}$ apart, in the cropped treatment on November 9, 2016. The ryegrass seeds were sown at $400 \mathrm{~kg} \mathrm{ha}^{-1}$ (because the rate of emergence in our research field was low) with $\mathrm{N}$ (ammonium sulfate) and $\mathrm{K}_{2} \mathrm{O}$ (potassium chloride) application rates of $100 \mathrm{~kg} \mathrm{ha}^{-1}$. The hairy vetch seeds were sown at $80 \mathrm{~kg} \mathrm{ha}^{-1}$ with $\mathrm{N}$ (ammonium sulfate) and $\mathrm{K}_{2} \mathrm{O}$ (potassium chloride) application rates of 50 and $100 \mathrm{~kg} \mathrm{ha}^{-1}$, respectively. Brown mustard seeds were sown at $80 \mathrm{~kg} \mathrm{ha}^{-1}$ with $\mathrm{N}$ and $\mathrm{K}_{2} \mathrm{O}$ application rates of $100 \mathrm{~kg} \mathrm{ha}^{-1}$. The tops of the cover crops were cut close to the ground and removed on April 24, 2017. For fallow, weeds were manually removed during the winter period. Soil biochemical

107 properties of the field after cultivation of cover crops are shown in Table S1.

We used a split-plot design to divide the $3 \mathrm{~m} \times 3 \mathrm{~m}$ of the cover crop experimental plots into $3.0 \mathrm{~m} \times 1.5 \mathrm{~m}$ plots for the two subsequent cropping plots (maize and soybean) (Fig. S1).

110 Then, both maize and soybean cropping plots were replicated three times in $3 \mathrm{~m} \times 3 \mathrm{~m}$ plots. The

111 maize and soybean seeds were sown at a spacing of $60 \mathrm{~cm} \times 15 \mathrm{~cm}$ on May 29, 2017. In

112 soybeans, the $\mathrm{N}$ and $\mathrm{K}_{2} \mathrm{O}$ application rates were 50 and $100 \mathrm{~kg} \mathrm{ha}^{-1}$, respectively. In maize, the $\mathrm{N}$ 
113 and $\mathrm{K}_{2} \mathrm{O}$ application rates were 150 and $100 \mathrm{~kg} \mathrm{ha}^{-1}$, respectively. No $\mathrm{P}$ fertilizer was applied in

114 both maize and soybean cropping in this study.

115

\section{Soil and root sampling and root staining}

117 The soil samples were randomly taken from ten points using a soil core sampler $(0-20 \mathrm{~cm}$ depth, $1184 \mathrm{~cm}$ diameter) in each replicate and pooled to one composite sample on April 24, 2017. Maize

119 and soybean root samples were taken at the 6 weeks after sowing on July 10, 2017. The root

120 samples in both maize and soybean were collected from nine plants (to a depth of $15 \mathrm{~cm}$, the

121 diameter of $20 \mathrm{~cm}$ ) per replicate. The root samples were maintained at $-80^{\circ} \mathrm{C}$ for DNA

122 extraction and measurement of AMF colonization. We stained the root samples with a 5\% (w/v)

123 black ink-vinegar solution (Vierheilig et al., 1998). The AMF root colonization in the maize and

124 soybean was measured according to Giovannetti \& Mosse (1980).

125

126 Measurement of the aboveground plant biomass of maize and soybean

127 The aboveground plant parts of eight plants in soybean and maize were cut close to the ground at

128 the 6 weeks after sowing and were randomly sampled on July 10, 2017. The aboveground maize

129 and soybean plant biomass were measured in all plots. The aboveground plant biomass by maize

130 and soybeans were determined after the samples were oven dried at $80^{\circ} \mathrm{C}$ for $48 \mathrm{~h}$.

132 DNA extraction from root samples

133 Genomic DNA was extracted from $100 \mathrm{mg}$ of fresh root samples using DNA suisui-P kit (RIZO,

134 Tsukuba, Japan) according to the manufacturer's instructions. Briefly, root samples were soaked

135 directly in liquid nitrogen, and then the root samples were crushed using a beads smasher MS-

136100 (TOMY, Tokyo, Japan). After crushing the roots, $360 \mu 1$ of DNA suisui-P lysis solution and

$13740 \mu \mathrm{l}$ of prepared additives with the DNA extraction kit were put into 1.5 -mL tubes. Up to $400 \mu 1$

138 of phenol: chloroform $(1: 1, \mathrm{v} / \mathrm{v})$ was added to the tubes and mixed vigorously using a vortex

139 mixer (Vortex-Genie 2, Scientific Industries, Tokyo). The samples were centrifuged at 15,000

$140 \mathrm{rpm}$ for $10 \mathrm{~min}$, at room temperature. After the centrifugation, $200 \mu \mathrm{l}$ of supernatant was 
141 transferred to a clean tube (1.5-mL) and $200 \mu$ (equal volume) of 2-propanol was added. After

142 that, the samples were centrifuged at 15,000 rpm for $10 \mathrm{~min}$, at room temperature. After this

143 centrifugation, the supernatant was discarded and added $800 \mu 1$ of $70 \%$ ethanol into the $1.5-\mathrm{mL}$

144 tube, and then this was centrifuged at $15,000 \mathrm{rpm}$ for $10 \mathrm{~min}$, at $4^{\circ} \mathrm{C}$. The supernatant was

145 discarded and the remaining pellet was dried. We added $50 \mu 1$ of Tris-EDTA (TE) buffer [1 mM

146 Tris ( $\mathrm{pH} 8.0), 0.1 \mathrm{mM}$ EDTA ( $\mathrm{pH} \mathrm{8.0)]} \mathrm{to} \mathrm{dissolve} \mathrm{the} \mathrm{pellet,} \mathrm{and} \mathrm{this} \mathrm{solution} \mathrm{served} \mathrm{as}$

147 template DNA for polymerase chain reaction (PCR). The genomic DNA pellet was stored at

$148-30^{\circ} \mathrm{C}$ until use in the PCR.

149

150 Polymerase chain reaction (PCR) amplification

151 The fragments in the fungal small subunit ribosomal DNA (SSU rDNA) were amplified using

152 the first-round PCR. The universal primer NS31 (Simon et al., 1992) and the fungus-specific

153 primer AM1 (Helgason et al., 1998) were used in the first PCR round to amplify the 5' end of the

154 SSU rDNA region for Glomeromycotina. To decrease variations in the PCR process, samples

155 were amplified in triplicate (Polz and Cavanaugh, 1998) using the fusion primer set in a PCR at

$15610 \mu \mathrm{l}$ per subsample. The PCR was performed in $10 \mu 1$ reaction mixtures with each containing $2 \times$

157 of reaction buffer, $0.4 \mu \mathrm{M}$ of forward and reverse primers $(10 \mu \mathrm{M}), 1 \mathrm{U}$ of Taq DNA polymerase

158 (KOD multi \& Epi, Toyobo, Japan), and $1 \mu 1$ of template DNA using a Mastercycler ep Gradient

159 (Eppendorf, Hamburg, Germany). The first-round PCR was performed according to the PCR

160 cycle of Liang et al. (2008). The first PCR products were diluted 10-fold and used as templates

161 for the second-round PCR using the primers AMV4.5NF and AMDGR (Lumini et al., 2010).

162 The second-round PCR was performed in $10 \mu \mathrm{l}$ reaction mixtures that each contained $2 \times$ of

163 reaction buffer, $0.3 \mu \mathrm{M}$ of forward and reverse primers $(10 \mu \mathrm{M}), 1 \mathrm{U}$ of Taq DNA polymerase

164 (KOD multi \& Epi, Toyobo, Japan), and $1 \mu 1$ of template DNA. The second-round PCR protocol

165 was composed of an initial treatment at $94^{\circ} \mathrm{C}$ for $2 \mathrm{~min} ; 45$ cycles of treatments at $98^{\circ} \mathrm{C}$ for $10 \mathrm{~s}$

166 and at $60^{\circ} \mathrm{C}$ for $10 \mathrm{~s}$. Gel electrophoresis separated amplicons on $1 \%$ agarose gel, and the

167 approximately 300 bp DNA amplicons were visualized by staining with ethidium bromide. 
169 Illumina MiSeq sequencing and molecular diversity of AMF communities in roots

170 Three independent PCR products were pooled together and purified using NucleoSpin Gel and

171 PCR Clean-up kit (Macherey-Nagel, Duren, Germany) to reduce potential early-round PCR

172 errors, and quantified using UV spectrophotometry (DS-11 NanoPad, DeNovix Inc., USA). The

173 purified PCR amplicons were normalized before an Illumina MiSeq platform sequencing. The

174 amplicons were paired-end (PE) sequenced on the Illumina MiSeq platform (Bioengineering Lab

175 Co., Ltd, Kanagawa, Japan). In total, 24 sequencing libraries were constructed and independently

176 sequenced. Sequence read processing was performed using QIIME version 1.9.1 (Caporaso et al., 177 2010).

178 The reads were truncated at any site that received an average quality score $<20$ over a $40 \mathrm{bp}$

179 sliding window, and the truncated reads shorter than $40 \mathrm{bp}$ were discarded using FASTX-Toolkit.

180 Then, PE reads were assembled according to their overlap sequence with a minimum overlap

181 length of $10 \mathrm{bp}$, while reads that could not be assembled were discarded. The clean sequences

182 were analyzed using the FLASH (Fast length adjustment of short reads). Chimeric sequences

183 were identified and removed using UCHIME in USEARCH. Operational taxonomic unit (OTU)

184 grouping was performed using Silva and NCBI Genbank at 97\% similarity. The representative

185 sequences were checked against NCBI GenBank. The raw sequence data are available in the

186 DNA Data Bank of Japan (DDBJ) (DDBJ Sequence Read Archive, DRA007103). Additionally,

187 we performed a rarefaction analysis using the vegan package in R 3.5.0.

188

189 Statistical analysis

190 A generalized linear model (GLM) was used to determine the effects of host identity and cover

191 cropping on each parameter in this study in the multcomp package in R 3.5.0. Data for the

192 significance of differences between subsequent host crop types among cover crop treatments

193 were assessed using Student's t-test. Differences among means were assessed using Tukey's test

194 ( $P$-values $<0.05)$ using the multcomp package in R 3.5.0. In addition, the amplicons are

195 relatively short $(<400 \mathrm{bp})$, the fungal community that was obtained after pyrosequencing, was

196 highly a good reflection of the fungal composition in the sample (Ihrnark et al., 2012). Moreover, 
197 Hill numbers (or the effective number of species) have been increasingly used to quantify the

198 species/taxonomic diversity of an assemblage because they represent an intuitive and statistically

199 rigorous alternative to other diversity indices (Chao et al. 2014; Hsieh et al., 2016). Thus,

200 diversity of AMF OTU communities were measured based on the first three Hill numbers, such

201 as species richness, Shannon diversity (the exponential of Shannon entropy), and Simpson

202 diversity (the inverse Simpson concentration) using the "renyi" function the vegan package in $\mathrm{R}$

203 3.5.0.

204 Additionally, the differences in the AMF community structures among host crop type and

205 cover cropping was also examined by a distance-based redundancy analysis (db-RDA) in the

206 vegan package in $\mathrm{R}$ 3.5.0 to analyze the relationship of cover crops and subsequent host crop

207 type with respect to AMF community structures. The environmental variable of cover cropping

208 and host crop type was coded as a dummy variable (0 and 1). Goodness-of-fit statistics $\left(R^{2}\right)$ of

209 measured factors fitted to the db-RDA ordination of the AMF community structures were

210 calculated using the "envfit" function in the vegan package with $P$-values based on 999

211 permutations (Oksanen, 2018). Differences in the AMF community structures between maize

212 and soybean were also determined by non-metric multidimensional scaling (NMDS) with the

213 "metaMDS" function. A permutational multivariate analysis of variance (PERMANOVA) was

214 performed with 999 permutations using the "Adonis" function in the vegan package in R 3.5.0 to

215 investigate if AMF community structures differed significantly between cover crops and

216 subsequent host crop type. The "Bray-Curtis" metric of AMF community structure was used in

217 the PERMANOVA and NMDS analysis (Chase et al., 2011).

218 Furthermore, we performed an analysis based on the multinomial species classification

219 method (CLAM test) with the "clamtest" function of the vegan package in R 3.5.0 (Chazdon et

220 al., 2011) to understand AMF OTUs showing a preference for maize or soybean. The CLAM test

221 uses a multinomial model based on estimated species relative abundance in two habitat or host

222 species (maize and soybean). The multinomial model implemented in the test minimizes biases

223 due to different sampling intensities between the two habitats or host species being compared.

224 The method permits a robust statistical classification of habitat specialists and generalists, 
225 without excluding rare species a priori (Chazdon et al. 2011). In this study, the model classifies

226 species into one of four groups: (1) generalists; (2) maize specialists; (3) soybean specialists; and

227 (4) too rare species.

228 In the diversity indices, db-RDA, PERMANOVA, NMDS, and CLAM test, we rarefied our

229 dataset down to the lowest OTU abundance to compare evenly between samples regardless of

230 sequencing depth (i.e. samples with greater sequencing depth can allow for greater detection of

231 low-abundance taxa compared with more shallowly sequenced samples).

232

233 Results

\section{AMF colonization and plant growth in maize and soybean roots}

235 Overall, our results showed that cover cropping impacted AMF colonization in maize roots,

236 whereas differences in AMF colonization of soybean were not impacted by cover cropping (Fig.

237 1). We found that AMF colonization of maize under Italian ryegrass and hairy vetch treatments

238 was significantly higher than that of brown mustard and bare fallow treatments. In soybean, a

239 similar tendency in AMF colonization with regard to maize cropping was observed. However, no

240 significant differences in AMF colonization of soybean were found among cover cropping

241 treatments.

242 According to Figure 2, the aboveground plant biomass in maize did not vary among cover 243 crop treatments in this study (Fig. 2A). The aboveground plant biomass under Italian ryegrass

244 and brown mustard treatments tended to be higher than that of hairy vetch and bare fallow

245 treatments. On the contrary, the aboveground plant biomass of soybean in the Italian ryegrass

246 plot was more than double than those of hairy vetch and bare fallow treatments (Fig. 2B).

247 Additionally, the aboveground plant biomass of soybeans in the brown mustard treatment was

248 higher than those of hairy vetch and bare fallow treatments, as the brown mustard is a non-host

249 crop.

250

251 General sequencing information and taxonomic richness 
252 In this study, a total of 1,087,375 paired-end sequences were obtained from the 24 libraries using 253 the AMV4.5NF/AMDGR primer set. Of these, 873,458 sequences belonged to Glomeromycotina

254 (corresponding to $80.3 \%$ of the total). We showed the OTU distributions of the obtained

255 sequences in root samples (Table S2). In total, 83 OTUs were found in the AMF communities

256 based on 97\% similarity after the rarefaction process (Fig. 3). The AMF OTUs were also

257 classified into one of four AMF families including Glomeraceae (average relative abundance:

258 60.7\%), Gigasporaceae (22.0\%), Acaulosporaceae (16.2\%) and uncultured Glomeromycotina in $259 \operatorname{roots}(1.1 \%)$.

260 Additionally, the OTU richness in maize after cultivation of brown mustard or bare fallow

261 was higher compared with that from roots after cultivation of Italian ryegrass and hairy vetch,

262 but this was not a significant difference (Fig. 4A). On the contrary, the Shannon $\left(H^{\prime}\right)$ and

263 Simpson $(1 / D)$ indices in hairy vetch were significantly lower than those of other cover cropping

264 treatments (Fig. 4B and 4C). In terms of other cover cropping treatments, no significant

265 differences in the Shannon and Simpson indices were found (Fig. 4B and 4C). However, in

266 soybean after cultivation of brown mustard or bare fallow, the OTU richness and Shannon index

267 was lower compared with those from roots after cultivation of Italian ryegrass and hairy vetch

268 (Fig. 4A and 4B). Moreover, at each parameter between maize and soybean roots, no significant

269 difference was found (Fig. 4A-4C).

270

271 Structures of AMF communities in the two different subsequent crops

272 Our results showed that the relative abundance of each AMF OTU and family tended to be

273 different among cover cropping treatments when we compared the AMF communities in maize

274 with that in soybean (Fig. S2A and S2B). Moreover, we found that the structure of AMF

275 communities in Italian ryegrass versus hairy vetch treatments, and brown mustard versus bare

276 fallow treatments in maize tended to shape a similar community structure. In Italian ryegrass and

277 hairy vetch treatments, Glomeraceae was predominant. On the contrary, Gigasporaceae and

278 Acaulosporaceae were predominant in brown mustard and bare fallow treatments. In soybean,

279 the structure of AMF communities in brown mustard versus bare fallow treatments also tended to 
280 shape a similar community structure (Fig. S2A). In hairy vetch, brown mustard and bare fallow

281 treatments, Glomeraceae were predominant, on the contrary, Gigasporaceae and

282 Acaulosporaceae were predominant only in Italian ryegrass treatment. Additionally, we found

283 that Glomeraceae was detected at a high frequency in both maize (56.2\%) and soybean roots

$284(62.2 \%)$ regardless of cover cropping treatments (Fig. S2A). Gigasporaceae was more abundant

285 in maize (25.0\%) compared with in soybean (20.6\%), and the relative abundance of

286 Acaulosporaceae in the maize (17.7\%) was larger than that in soybean (16.2\%). Among the

287 OTUs of Glomeraceae, the OTUs of uncultured Glomus (Accession No., LT217508; LT723917;

288 LT217431) were detected at a much higher frequency in both maize $(28.8 \% ; 8.5 \% ; 8.3 \%$,

289 respectively) and soybean roots (22.4\%; 18.4\%; 13.5\%, respectively) (Table S4 and Fig. S2B).

290 In turn, the OTU of Rhizophagus irregularis (HF968834) was also detected at a higher frequency

291 in both maize (5.6\%) and soybean roots (3.4\%). Among the OTUs of Gigasporaceae, the OTU

292 of Cetraspora pellucida (KX879059) was highly detected at a much higher frequency in both

293 maize (19.5\%) and soybean roots (16.1\%). Additionally, the OTU of uncultured Acaulospora

294 (LN890608) was detected at a much higher frequency in both maize (13.5\%) and soybean roots

295 (12.5\%) among the OTUs of Acaulosporaceae.

296

297 Host preference of AMF communities in the two different subsequent crops

298 The AMF OTUs in various taxonomic lineages were also classified as "generalists," commonly

299 found in both subsequent crop species according to the multinomial species classification method

300 (CLAM) test (Table S3 and S4). The proportion of common generalists in roots in this

301 experiment among Italian ryegrass, hairy vetch or brown mustard versus bare fallow was $77.1 \%$,

$30268.8 \%$ and 18.8\%, respectively (Fig. 5A-5C). The proportion of detected OTUs that occurred

303 specifically in only ryegrass, hairy vetch or brown mustard was $8.4 \%, 12.5 \%$, and $33.8 \%$,

304 respectively. Moreover, detected OTUs that occurred specifically in only bare fallow measured

$3054.8 \%, 12.5 \%$, and $41.2 \%$, respectively, when comparing with Italian ryegrass, hairy vetch or

306 brown mustard treatments. Additionally, most of the OTUs in root samples were common

307 between maize and soybean, and the proportion of common generalists in this experiment for 
308 maize and soybean roots was $79.5 \%$ (Fig. 6). Detected OTUs that occurred specifically in only 309 maize and soybean were $9.6 \%$ and $10.8 \%$, respectively.

310

\section{Relationships between AMF communities of cover cropping and subsequent host crops}

312 We used distance-based redundancy analysis (db-RDA) to identify the relationships among AMF 313 communities in maize and soybean roots with that in cover crop management (Fig. 7A and 7B).

314 The db-RDA trends clearly showed that the cover cropping noticeably altered the AMF

315 community structure in the maize and soybean roots. In maize, the ordination diagram indicates

316 that Italian ryegrass $\left(R^{2}=0.787, P=0.003\right)$, hairy vetch $\left(R^{2}=0.721, P=0.01\right)$ and bare fallow

$317\left(R^{2}=0.492, P=0.028\right)$ contributed significantly to the variation in AMF root communities (Fig.

318 7A). However, brown mustard $\left(R^{2}=0.064, P=0.737\right)$ did not contribute to the variation in the

319 AMF root communities. In soybean, the ordination diagram indicates that Italian ryegrass $\left(R^{2}=\right.$

$3200.558, P=0.046)$ and bare fallow $\left(R^{2}=0.533, P=0.039\right)$ contributed significantly to the

321 variation in the AMF root communities (Fig. 7B). However, hairy vetch $\left(R^{2}=0.410, P=0.076\right)$

322 and brown mustard $\left(R^{2}=0.475, P=0.055\right)$ did not contribute to the variation in the AMF root

323 communities. A permutational multivariate analysis of variance (PERMANOVA) was also

324 carried out to examine the effect of cover cropping on the AMF root communities in maize and

325 soybean. The PERMANOVA showed that cover cropping significantly affected the AMF root

326 community structure (maize; $F=4.647, P<0.05$, soybean; $F=6.339, P<0.001$ ) (Fig. 7A and

327 7B).

328 Additionally, we used non-metric multidimensional scaling (NMDS) to identify the

329 differences in the AMF communities between maize and soybean (Fig. 8). The differentiation of

330 AMF communities between the two subsequent host crop species was not statistically significant

331 (host crop; $F=1.238, P>0.05$, cover cropping; $F=2.048, P>0.05$ ). However, we found that

332 the interaction with host crop species and cover cropping on the differences in the AMF

333 communities in the maize and soybean roots was significantly different (interaction; $F=8.565, P$

$334<0.001)$. 


\section{Discussion}

\section{Impact of cover cropping on AMF root colonization}

338 Previous studies have shown that the introduction of cover crops or fallow affects AMF

339 colonization of subsequent cash crops (Isobe et al., 2014; Karasawa \& Takahashi, 2015; Higo et

340 al., 2018a). Indeed, in the current study, brown mustard and bare fallow treatments significantly

341 affected the AMF colonization of subsequent maize; however, these treatments did not affect the

342 AMF colonization of subsequent soybean (Fig. 1), which is a finding that is in partial agreement

343 with the results of previous studies (Karasawa et al., 2002; Karasawa \& Takebe, 2012). Some

344 previous findings also indicated that the introduction of Brassicaceae plants reduced AMF root

345 colonization in subsequent crops during early growth stages compared with the introduction of

346 host crops (Sorensen et al., 2005; Koide \& Peoples, 2012). Because brown mustard (a member of

347 Brassicaceae) does not form symbiotic relationships with AMF in its roots due to the release of

348 antifungal compounds, such as mustard oils or isothiocyanates. Indeed, antifungal compounds,

349 such as isothiocyanates, decompose in soil owing to microbial effects and responses to organic

350 matter (Morra \& Kirkegaard, 2002). Schreiner and Koide (1993) showed that extracts from

351 Brassicaceae roots reduced AMF spore germination after 5 and 7 days. However, AMF spore

352 germination recovered to normal conditions after about 14 days, thereby suggesting that

353 isothiocyanates and mustard oils may have an antimicrobial effect on soil microorganisms,

354 including AMF spores. In fact, the maize and soybean growth performance in the early growth

355 stage, even after brown mustard treatment, did not reduce with decreasing AMF root

356 colonization (Fig. 2A and 2B), although brown mustard is a non-host crop, in agreement with the

357 results of Higo et al. (2018b). Thus, adding brown mustard or fallow in a rotation with maize and

358 soybean may not necessarily have negative impacts on the performance of subsequent maize and

359 soybean in early growth stages.

360

\section{Distribution of AMF communities in maize and soybean roots}

362 Our results showed that the representatives of Glomeraceae (including a genus of Glomus and 363 Rhizophagus) were found to be the main family, although Gigasporaceae (including a genus of 
364 Cetraspora, Gigaspora, and Racocetra), Acaulosporaceae (including a genus of Acaulospora)

365 and uncultured Glomeromycotina were found in both maize and soybean roots (Fig. S2). These

366 results are similar to the findings of published studies confirming that the AMF taxa of

367 Glomeraceae are the most abundant in the AMF communities of maize (Isobe et al., 2011; Wang

368 et al., 2017; Higo et al., 2018b) and soybean roots (Higo et al., 2014, 2018a; García de León et

369 al., 2018; Faggioli et al., 2019). The AMF taxa of Glomeraceae are particularly predominant in

370 roots and arable soils (Senés-Guerrero et al., 2016; Xiang et al., 2016; Xu et al., 2017; Zhao et al.,

371 2017) because they are better adapted to disturbed environments than other families in addition

372 to having high sporulation rates for rapid recovery (Oehl et al., 2003). Moreover, Glomeraceae

373 colonize throughout fragments of hyphae or mycorrhizal roots, thereby forming a hyphal

374 anastomosis (Giovannetti et al., 1999), and therefore possessing the ability to reconstruct a

375 network after mechanical disruption. However, Gigasporaceae of AMF propagates throughout

376 spore dispersal or infection from an intact hypha (Biermann \& Linderman, 2006; Schalamuk \&

377 Cabello, 2010). Thus, these factors promote the survival and spread of Glomeraceae family

378 members in agricultural ecosystems, and the occurrence of this phenomenon can also be the

379 result of adaptation to agroecological environments.

380 Additionally, Clavel et al. (2011) indicated that in general, taxa of generalists are thought to

381 be related to taxa of specialists with undisturbed habitats and disturbed habitats. Johnson (1993)

382 has reported that AMF have different niches and are well known to prefer inhabiting different

383 soils. Host plant types and environmental filters may favor AMF taxa that grow better in soils

384 (Dumbrell et al., 2010). In fact, Börstler et al. (2008) and Séry et al. (2018) suggested that a

385 Glomeraceae such as the generalist, $R$. irregularis, has been observed in many different types of

386 fields and can have a high tolerance for environmental filters such as tillage. On the contrary,

387 Gottshall et al. (2017) reported that AMF taxa of Gigasporaceae were affected by agricultural

388 management practices with a low level of soil disturbance. Faggioli et al. (2019) also suggested

389 that abundance of Gigasporaceae can rely on no-tillage practice. Additionally, intensive

390 agricultural practices may reduce the taxa richness and change the AMF community structures

391 according to favoring certain AMF taxa and disfavouring other AMF taxa (Gottshall et al., 2017). 
392 This phenomenon shows the shift in the occurrence of generalist and specialist AMF taxa with

393 respect to a range of host plant species or habitat (Helgason et al., 2007; Oehl et al., 2010). Thus,

394 the fluctuation in abundance of AMF taxa (generalists, specialists and rare taxa) as a result of

395 cover cropping or host crops (maize and soybean) (Fig. 5 and 6, Fig. S2, Table S3 and S4) could

396 link to the preference of host identity or inhabiting preferable agricultural practices such as cover

397 cropping among AMF taxa in maize and soybean roots.

398 Additionally, there are few but increasing evidence of the spatial distribution of AMF

399 communities in soil at small scales using molecular techniques. For example, Mummey and

400 Rillig (2008) also indicated the difference in the spatial distribution of AMF communities at a

401 small $(1 \mathrm{~m} \mathrm{x} 1 \mathrm{~m})$ scale in a temperate grassland. Wolfe et al. (2007) also found that the spatial

402 variation of AMF communities to be within a $2 \mathrm{~m}$ x $2 \mathrm{~m}$ scale. In this study, the $3 \mathrm{~m} \times 3 \mathrm{~m}$ scale

403 of our research plots may be small for performing experiments to determine the distribution of

404 AMF communities in agricultural practices. However, we considered that the spatial distribution

405 of specific AMF communities of our study responded to the presence of the crop in our crop

406 rotational system, in accordance with the findings of previous studies (Wolfe et al., 2007;

407 Mummey \& Rillig, 2008). Taken together, our research plot scale is complete enough to

408 compare the diversity of AMF communities with the impact of cover cropping and host identity.

409

410 Impact of cover cropping on the diversity of AMF communities

411 Although the benefits of a host plant may differ according to individual AMF taxa, there are little

412 data with respect to how the diversity of AMF communities varies with cover cropping practices.

413 To date, Higo et al. (2014) have demonstrated that the diversity of AMF communities colonizing

414 subsequent soybean roots in a cover crop rotations system is clearly changed by rotation year,

415 suggesting that climate or other environmental filters are more important than winter cover

416 cropping. Furthermore, Higo et al. (2018b) and Turrini et al. (2016) showed that a difference in

417 the structure of AMF communities colonizing subsequent maize roots in a cover crop rotation is

418 independent of the identity of preceding crops. However, these studies used separate plots for the

419 cover crop rotation experiment to assess the effect of cover crops on the AMF communities in 
420

421

422

423

424

425

426

427

428

429

430

431

432

\section{3}

434

435

436

437

438

439

440

441

442

443

444

445

446

maize or soybean roots. Thus, we examined three cover crop treatments (Italian ryegrass, hairy vetch, and brown mustard) and bare fallow for the diversity of AMF colonizing both subsequent maize and soybean roots. We found that hairy vetch before planting maize had a negative impact on the diversity of AMF in roots of maize, but not for that of soybean (Fig. 4B and 4C). In soybeans, brown mustard before planting soybean had a negative impact on the diversity of AMF in roots. Additionally, the shift of AMF communities in both maize and soybean was obvious from the results of db-RDA, which showed how cover cropping changed the AMF community structure in both subsequent crop roots (Fig. 6A and 6B), in agreement with the observations of a previous study (Higo et al., 2018a, 2018b). These findings indicate that cover crop species may induce a shift in the diversity and structure of AMF communities in soils, and the differences in the soil AMF communities after the different types of cover cropping may change the diversity of AMF communities in subsequent crops.

\section{Impact of host identity on the diversity of AMF communities}

Several studies have reported that host preference between host plants and AMF taxa may impact AMF community structure (Helgason et al., 2002; Yang et al., 2012). We expected that if host identity is a strong factor in determining AMF communities compared with cover cropping in the split-plot of our experiment, the AMF community structure associated with maize and soybean roots after cover cropping would be distinct host AMF community structures between maize and soybean roots. This would hold true even if different cover crop treatments were to shape a specific assemblage of AMF taxa in soils before planting maize and soybean in our cover crop rotation. However, our NMDS and PERMANOVA result demonstrated that host identity did not change the AMF community structure of maize and soybean roots (Fig. 8). Furthermore, host identity did not impact the richness, diversity, or structure of the AMF community in the roots of maize and soybean at the early growth stage, and this finding was somewhat unexpected.

45 Gosling et al. (2013) reported that soil P concentration had a greater impact on host identity. On the contrary, abiotic environmental filters, such as land-use type (Bainard et al., 2014), growing 
447 season (Higo et al., 2015b), and soil P (Bainard et al., 2014), appear to override the impact of 448 host identity if their impacts are large enough compared with host identity.

449 Additionally, Isobe et al. (2011) have shown that the AMF community structure in soybeans 450 grown in cool and temperate regions are drastically different, thus suggesting climate condition, 451 such as growth temperature, can also be a strong determinant in shaping AMF community 452 structures. To date, only a few studies have also shown that land-use type and host identity have 453 interactive effects on root AMF community structure in grasslands (Vályi et al., 2015; Ciccolini 454 et al., 2016) and agricultural fields (Higo et al., 2015b, 2016; Ciccolini et al., 2016), whereas 455 interactions between land use and other factors, such as soil biochemical properties, have also 456 been reported in temperate areas (Jansa et al., 2014; Ciccolini et al., 2015). Indeed, a specific 457 reason for why there was a significant interaction in the AMF communities between maize and 458 soybean, was uncertain in this study (Fig. 8). Thus, we hypothesize that one possible explanation 459 for the consistency in AMF communities between both subsequent crops may be that the impacts 460 of specific root exudate patterns in both maize and soybean on the host selectivity of AMF taxa 461 may be weakened due to planting maize and soybean within the same plot, or may be weakened 462 at a too early growth stage, as suggested by Higo et al. (2015b) and Borrell et al. (2016).

463 However, how and whether the selectivity of the host plant impacts the pattern of AMF 464 communities in agricultural systems, remains unknown. Thus, further investigation into the 465 relationships among a pattern of AMF communities would be required to better understand 466 whether and how host selectively impacts the AMF communities in cover crop rotational 467 systems.

\section{Conclusions}

470 In conclusion, cover cropping can be an important factor for shaping AMF communities in maize 471 and soybean roots rather than their host identity in a cover crop rotation. In addition, different 472 cover crop species may have different influences on the diversity of AMF community structure 473 in both maize and soybean roots. Additionally, interactions of cover cropping and host identity 474 may partially relate to shaping the diversity and structure of AMF communities in maize and 
475 soybean roots in this study. These differences in the AMF community structure may relate to 476 maize and soybean production in cover crop rotational systems. However, we still need to clarify

477 whether and how host identity interacts with the diversity and structure of AMF communities 478 associated with maize and soybean in cover cropping systems. This knowledge will give useful 479 information on appropriate cover crop choices in cover crop rotational systems.

Bainard LD, Bainard JD, Hamel C, Gan Y. 2014. Spatial and temporal structuring of

\section{References} arbuscular mycorrhizal communities is differentially influenced by abiotic factors and host crop in a semi-arid prairie agroecosystem. FEMS Microbiology Ecology 88(2):333-344

Berruti A, Bianciotto V, Lumini E. 2018. Seasonal variation in winter wheat field soil arbuscular mycorrhizal fungus communities after non-mycorrhizal crop cultivation. Mycorrhiza doi: 10.1007/s00572-018-0845-9

Biermann B, Linderman RG. 2006. Use of vesicular-arbuscular mycorrhizal roots, intraradical vesicles and extraradical vesicles as inoculum. New Phytologist 95(1):97-105

Börstler B, Raab PA, Thiéry O, Morton JB, Redecker D. 2008. Genetic diversity of the arbuscular mycorrhizal fungus Glomus intraradices as determined by mitochondrial large subunit rRNA gene sequences is considerably higher than previously expected. New Phytologist 180(2):452-465

Borrell AN, Shi Y, Gan Y, Bainard LD, Germida JJ, Hamel C. 2016. Fungal diversity associated with pulses and its influence on the subsequent wheat crop in the Canadian prairies. Plant and Soil 414(1-2):13-31

Caporaso JG, Kuczynski J, Stombaugh J, Bittinger K, Bushman FD, Costello EK, Fierer N, Peña AG, Goodrich JK, Gordon JI, Huttley GA, Kelley ST, Knights D, Koenig JE, Ley RE, Lozupone CA, McDonald D, Muegge BD, Pirrung M, Reeder J, Sevinsky JR, Turnbaugh PJ, Walters WA, Widmann J, Yatsunenko T, Zaneveld J, Knight R. 2010. QIIME allows analysis of high-throughput community sequencing data. Nature Methods 7(5):335-336 
503 Chase JM, Kraft NJB, Smith KG, Vellend M, Inouye BD. 2011. Using null models to 504 disentangle variation in community dissimilarity from variation in $\alpha$-diversity. Ecosphere $505 \quad 2(2): 1-11$

506 Chao A, Gotelli NJ, Hsieh TC, Sander EL, Ma KH, Colwell Ellison AM. 2014. Rarefaction 507 and extrapolation with Hill numbers: a framework for sampling and estimation in species 508 diversity studies. Ecological Monographs 84(1):45-67

509 Chazdon RL, Chao A, Colwell RK, Lin SY, Norden N, Letcher SG, Clark DB, Finegan B,

510 Arroyo JP. 2011. A novel statistical method for classifying habitat generalists and $511 \quad$ specialists. Ecology 92(6):1332-1343

512 Chiu CH, Chao A. 2016. Estimating and comparing microbial diversity in the presence of $513 \quad$ sequencing errors. PeerJ 4:e1634

514 Ciccolini V, Bonari E, Pellegrino E. 2015. Land-use intensity and soil properties shape the composition of fungal communities in Mediterranean peaty soils drained for agricultural purposes. Biology and Fertility of Soils 51(6):719-731

517 Ciccolini V, Ercoli L, Davison J, Vasar M, Öpik M, Pellegrino E. 2016. Land-use intensity

518 and host plant simultaneously shape the composition of arbuscular mycorrhizal fungal communities in a Mediterranean drained peatland. FEMS Microbiology Ecology 92(12). doi.org/10.1093/femsec/fiw186

Clark A. 2008. Managing cover crops profitably. 3rd ed. Sustainable agriculture network, 522 Beltsville, MD

523 Clavel J, Julliard R, Devictor V. 2011. Worldwide decline of specialist species: toward a 524 global functional homogenization? Frontiers in Ecology and the Environment 9(4):222-228

525 Cofré MN, Ferrari AE, Becerra A, Domínguez L, Wall LG, Urcelay C. 2017. Effects of 526 cropping systems under no-till agriculture on arbuscular mycorrhizal fungi in Argentinean 527 Pampas. Soil Use and Management 33(2):364-378

528 Dumbrell AJ, Nelson M, Helgason T, Dytham C, Fitter AH. 2010. Relative roles of niche and 529 neutral processes in structuring a soil microbial community. The ISME Journal 4(3):337$530 \quad 345$ 
531 Faggioli VS, Cabello MN, Grillic G, Vasar M, Covacevich, F, Öpik M. 2019. Root colonizing 532 and soil borne communities of arbuscular mycorrhizal fungi differ among soybean fields

533

534

535

536

537

538

539

540

541

542

543

544

545

546

547

548

549

550

551

552

553

554

555

556

557

558 with contrasting historical land use. Agriculture, Ecosystems \& Environment 269(1):174182

García de León D, Cantero JJ, Moora M, Öpik M, Davison J, Vasar M, Jairus T, Zobel M. 2018. Soybean cultivation supports a diverse arbuscular mycorrhizal fungal community in central Argentina. Applied Soil Ecology 124:289-297

García-González I, Quemada M, Gabriel JL, Hontoria C. 2016. Arbuscular mycorrhizal fungal activity responses to winter cover crops in a sunflower and maize cropping system. Applied Soil Ecology 102:10-18

García-González I, Hontoria C, Gabriel JL, Alonso-Ayuso M, Quemada M. 2018. Cover crops to mitigate soil degradation and enhance soil functionality in irrigated land. Geoderma 322:81-88

Gavito ME, Miller MH. 1998. Early phosphorus nutrition, mycorrhizae development, dry matter partitioning and yield of maize. Plant and Soil 199(2):177-186

Giovannetti M, Mosse B. 1980. An evaluation of techniques for measuring vesicular arbuscular mycorrhizal infection in roots. New Phytologist 84(3):489-500

Giovannetti M, Azzolini D, Citernesi AS. 1999. Anastomosis formation and nuclear and protoplasmic exchange in arbuscular mycorrhizal fungi. Applied and Environmental Microbiology 65(12):5571-5575

Gosling P, Hodge A, Goodlass G, Bending GD. 2006. Arbuscular mycorrhizal fungi and organic farming. Agriculture, Ecosystems \& Environment 113(1):17-35

Gosling P, Mead A, Proctor M, Hammond JP, Bending GD. 2013. Contrasting arbuscular mycorrhizal communities colonizing different host plants show a similar response to a soil phosphorus concentration gradient. New Phytologist 198(2):546-556

Gottshall CB, Cooper M, Emery SM. 2017. Activity, diversity and function of arbuscular mycorrhizae vary with changes in agricultural management intensity. Agriculture, Ecosystems \& Environment 241(1):142-149 
559

560

561

562

563

564

565

566

567

568

569

570

571

572

573

574

575

576

577

578

579

580

581

582

583

584

585

Helgason T, Daniell TJ, Husband R, Fitter AH, Young JPW. 1998. Ploughing up the woodwide web? Nature 394(6692):431-431

Helgason T, Merryweather JW, Denison J, Wilson P, Young JPW, Fitter AH. 2002.

Selectivity and functional diversity in arbuscular mycorrhizas of co-occurring fungi and plants from a temperate deciduous woodland. Journal of Ecology 90(2):371-384

Helgason T, Merryweather JW, Young JPW, Fitter A. 2007. Specificity and resilience in the arbuscular mycorrhizal fungi of a natural woodland community. Journal of Ecology 95(4): 623-630

Higo M, Isobe K, Drijber RA, Kondo T, Yamaguchi M, Takeyama S, Suzuki Y, Niijima D, Matsuda Y, Ishii R, Torigoe Y. 2014. Impact of a 5-year winter cover crop rotational system on the molecular diversity of arbuscular mycorrhizal fungi colonizing roots of subsequent soybean. Biology and Fertility of soils 50(6):913-926

Higo M, Isobe K, Kang D-J, Ujiie K, Drijber RA, Ishii R. 2010. Inoculation with arbuscular mycorrhizal fungi or crop rotation with mycorrhizal plants improves the growth of maize in limed acid sulfate soil. Plant Production Science 13(1):74-79

Higo M, Isobe K, Kondo T, Yamaguchi M, Takeyama S, Drijber RA, Torigoe Y. $2015 a$. Temporal variation of the molecular diversity of arbuscular mycorrhizal communities in three different winter cover crop rotational systems. Biology and Fertility of soils 51(1):2132

Higo M, Isobe K, Matsuda Y, Ichida M, Torigoe Y 2015b. Influence of sowing season and host crop identity on the community structure of arbuscular mycorrhizal fungi colonizing roots of two different gramineous and leguminous crop species. Advances in Microbiology 5(2):107-116

Higo M, Isobe K, Miyazawa Y, Matsuda Y, Drijber RA, Torigoe Y. 2016. Molecular diversity and distribution of indigenous arbuscular mycorrhizal communities colonizing roots of two different winter cover crops in response to their root proliferation. Journal of Microbiology 54(2):86-97 
586 Higo M, Isobe K, Yamaguchi M, Drijber RA, Jeske ES, Ishii R. 2013. Diversity and vertical 587 distribution of indigenous arbuscular mycorrhizal fungi under two soybean rotational systems. Biology and Fertility of Soils 49(8):1085-1096

Higo M, Sato R, Serizawa A, Takahashi Y, Gunji K, Tatewaki Y, Isobe K. 2018a. Can phosphorus application and cover cropping alter arbuscular mycorrhizal fungal communities and soybean performance after a five-year phosphorus-unfertilized crop rotational system? PeerJ 6:e4606

Higo M, Takahashi Y, Gunji K, Isobe K. 2018b. How are arbuscular mycorrhizal associations related to maize growth performance during short-term cover crop rotation? Journal of the Science of Food and Agriculture 98(4):1388-1396

Hsieh TC, Ma KH, Chao A. 2016. iNEXT: an R package for rarefaction and extrapolation of species diversity (Hill numbers). Methods in Ecology and Evolution 7(12):1451-1456

Ihrmark K, Bodeker ITM, Cruz-Martinez K, Friberg H, Kubartova A, Schenck J, Strid Y, Stenlid J, Brandstrom-Durling M, Clemmensen KE, Lindahl BD. 2012. New primers to amplify the fungal ITS2 region-evaluation by 454-sequencing of artificial and natural communities. FEMS Microbiology Ecology 82(3):666-677

Isobe K, Maruyama K, Nagai S, Higo M, Maekawa T, Mizonobe G, Drijber RA, Ishii R. 2011. Arbuscular Mycorrhizal Fungal Community Structure in Soybean Roots: Comparison

611 Johnson NC. 1993. Can Fertilization of Soil Select Less Mutualistic Mycorrhizae? Ecological between Kanagawa and Hokkaido, Japan. Advances in Microbiology 1(1):13-22

Jansa J, Erb A, Oberholzer H-R, Šmilauer P, Egli S. 2014. Soil and geography are more important determinants of indigenous arbuscular mycorrhizal communities than management practices in Swiss agricultural soils. Molecular Ecology 23(8):2118-2135 Applications 3(4):749-757 
613 Kahiluoto H, Ketoja E, Vestberg M. 2012. Plant-available P supply is not the main factor 614 determining the benefit from arbuscular mycorrhiza to crop P nutrition and growth in 615 contrasting cropping systems. Plant and Soil 350(1-2):85-98

616 Karasawa T, Kasahara Y, Takebe M. 2002. Differences in growth responses of maize to 617 preceding cropping caused by fluctuation in the population of indigenous arbuscular 618 mycorrhizal fungi. Soil Biology and Biochemistry 34(6):851-857

619 Karasawa T, Takahashi S. 2015. Introduction of various cover crop species to improve soil 620 biological P parameters and P uptake of the following crops. Nutrient Cycling in 621 Agroecosystems 103(1):15-28

622 Karasawa T, Takebe M. 2012. Temporal or spatial arrangements of cover crops to promote 623

624 arbuscular mycorrhizal colonization and $\mathrm{P}$ uptake of upland crops grown after nonmycorrhizal crops. Plant and Soil 353(1-2):355-366

Koide RT and Peoples MS. 2012. On the nature of temporary yield loss in maize following canola. Plant and Soil 360(1-2):259-269

627 Lehman RM, Taheri WI, Osborne SL, Buyer JS, Douds DD. 2012. Fall cover cropping can 628 increase arbuscular mycorrhizae in soils supporting intensive agricultural production. $629 \quad$ Applied Soil Ecology 61:300-304

630 Lumini E, Orgiazzi A, Borriello R, Bonfante P, Bianciotto V. 2010. Disclosing arbuscular mycorrhizal fungal biodiversity in soil through a land-use gradient using a pyrosequencing approach. Environmental Microbiology 12(8):2165-2179

Morra MJ, Kirkegaard JA. 2002. Isothiocyanate release from soil-incorporated Brassica 634 tissues. Soil Biology and Biochemistry 34:1683-1690

635 Mummey DL, Rillig MC. 2008. Spatial characterization of arbuscular mycorrhizal fungal 636 molecular diversity at the submetre scale in a temperate grassland. FEMS Microbiology

638 Njeru EM, Avio L, Sbrana C, Turrini A, Bocci G, Bàrberi P, Giovannetti M. 2014. First 639 evidence for a major cover crop effect on arbuscular mycorrhizal fungi and organic maize growth. Agronomy for Sustainable Development 34(4):841-848 
641

642

643

644

645

646

647

648

649

650

651

652

653

654

655

656

657

658

659

660

661

662

663

664

665

666

667

Oehl F, Laczko E, Bogenrieder A, Stahr K, Bösch R, van der Heijden M, Sieverding E.

2010. Soil type and land use intensity determine the composition of arbuscular mycorrhizal fungal communities. Soil Biology and Biochemistry 42:724-738

Oehl F, Sieverding E, Ineichen K, Mäder P, Boller T, Wiemken A. 2003. Impact of Land use intensity on the species diversity of arbuscular mycorrhizal fungi in agroecosystems of Central Europe. Applied and Environmental Microbiology 69(5):2816-2824

Ohsowski BM, Zaitsoff PD, Öpik M, Hart MM. 2014. Where the wild things are: looking for uncultured Glomeromycota. New Phytologist 204(1):171-179

Oksanen J , Blanchet F G , Kindt R, Legendre P, O'Hara R B , Simpson G L, Solymos P, Stevens M H H, Wagner H. 2018. vegan: Community Ecology Package. R package version 2.5-2. https://cran.r-project.org/web/packages/vegan/index.html

Polz MF, Cavanaugh CM. 1998. Bias in template-to-product ratios in multitemplate PCR. Applied and Environmental Microbiology 64:3724-3730

Schalamuk S, Cabello M. 2010. Arbuscular mycorrhizal fungal propagules from tillage and notillage systems: possible effects on Glomeromycota diversity. Mycologia 102(2):261-268

Schreiner RP, Koide RT. 1993. Mustards, mustard oils and mycorrhizas. New Phytologist 123(1):107-113

Senés-Guerrero C, Schüßler A. 2016. A conserved arbuscular mycorrhizal fungal core-species community colonizes potato roots in the Andes. Fungal Diversity 77(1):317-333

Séry, DJM, van Tuinen D, Drain A, Mounier A, Zézé A. 2018. The genus Rhizophagus dominates arbuscular mycorrhizal fungi communities in contrasted cassava field soils in Côte d'Ivoire. Rhizosphere 7:8-17

Simon L, Lalonde M, Bruns TD. 1992. Specific amplification of 18S fungal ribosomal genes from vesicular-arbuscular endomycorrhizal fungi colonizing roots. Applied and Environmental Microbiology 58(1):291-295

Smith SE, Read DJ. 2008. Arbuscular mycorrhizaes. In Smith SE, Read DJ (Eds), Mycorrhizal symbiosis 3rd Edition. Academic Press, London, pp.13-187 
668 Snapp SS, Swinton SM, Labarta R, Mutch D, Black JR, Leep R, Nyiraneza J, O’Neil K.

669

670

671

672

673

674

675

676

677

678

679

680

681

682

683

684

685

686

687

688

689

690

691

692

693

694

695

2005. Evaluating cover crops for benefits, costs and performance within cropping system niches. Agronomy Journal 97(1):322-332

Sorensen JN, Larsen J, Jakobsen I. 2005. Mycorrhiza formation and nutrient concentration in leeks (Allium porrum) in relation to previous crop and cover crop management on high $\mathrm{P}$ soils. Plant and Soil 273(1-2):101-114

Turrini A, Sbrana C, Avio L, Njeru EM, Bocci G, Bàrberi P, Giovannetti M. 2016. Changes in the composition of native root arbuscular mycorrhizal fungal communities during a shortterm cover crop-maize succession. Biology and Fertility of Soils 52(5):643-653

Vályi K, Rillig MC, Hempel S. 2015. Land-use intensity and host plant identity interactively shape communities of arbuscular mycorrhizal fungi in roots of grassland plants. New Phytologist 205(4):1577-1586

Vierheilig H, Coughlan AP, Wyss U, Piché Y. 1998. Ink and vinegar, a simple staining technique for arbuscular-mycorrhizal fungi. Applied and Environmental Microbiology 64(12):5004-5007

Wang C, White PJ, Li C. 2017. Colonization and community structure of arbuscular mycorrhizal fungi in maize roots at different depths in the soil profile respond differently to phosphorus inputs on a long-term experimental site. Mycorrhiza 27(4):369-381

Wolfe BE, Mummey DL, Rillig MC, Klironomos JN. 2007. Small-scale spatial heterogeneity of arbuscular mycorrhizal fungal abundance and community composition in a wetland plant community. Mycorrhiza 17(3):175-183

Xiang X, Gibbons SM, He J-S, Wang C, He D, Li Q, Ni Y, Chu H. 2016. Rapid response of arbuscular mycorrhizal fungal communities to short-term fertilization in an alpine grassland on the Qinghai-Tibet Plateau. PeerJ 4:e2226

Xu X, Chen C, Zhang Z, Sun Z, Chen Y, Jiang J, Shen Z. 2017. The influence of environmental factors on communities of arbuscular mycorrhizal fungi associated with Chenopodium ambrosioides revealed by MiSeq sequencing investigation. Scientific Reports $7: 45134$ 
696 Yang H, Zang Y, Yuan Y, Tang J, Chen X. 2012. Selectivity by host plants affects the 697 distribution of arbuscular mycorrhizal fungi: evidence from ITS rDNA sequence metadata. 698 BMC Evolutionary Biology 12(1):50

699 Zhao H, Li X, Zhang Z, Zhao Y, Yang J, Zhu Y. 2017. Species diversity and drivers of $700 \quad$ arbuscular mycorrhizal fungal communities in a semi-arid mountain in China. PeerJ $701 \quad 5: e 4155$ 


\section{Figure 1 (on next page)}

Boxplots illustrating differences in group averages in root colonization of arbuscular mycorrhizal fungi (AMF) in maize and soybean at 6 weeks after sowing.

Bold horizontal lines represent median values; box margins \pm SE and vertical lines represent minimum and maximum values of the groups. 1) Different letters in the maize or soybean plots among the cover crop treatments show a significant difference according to Tukey's test at the $5 \%$ level. 2) R.M, V.M, M.M and F.M show the AMF root colonization of maize after cultivation of Italian ryegrass, hairy vetch, brown mustard cropping or bare fallow, respectively. R.S, V.S, M.S and F.S show the AMF root colonization of soybean after cultivation of Italian ryegrass, hairy vetch, brown mustard cropping or bare fallow, respectively. 


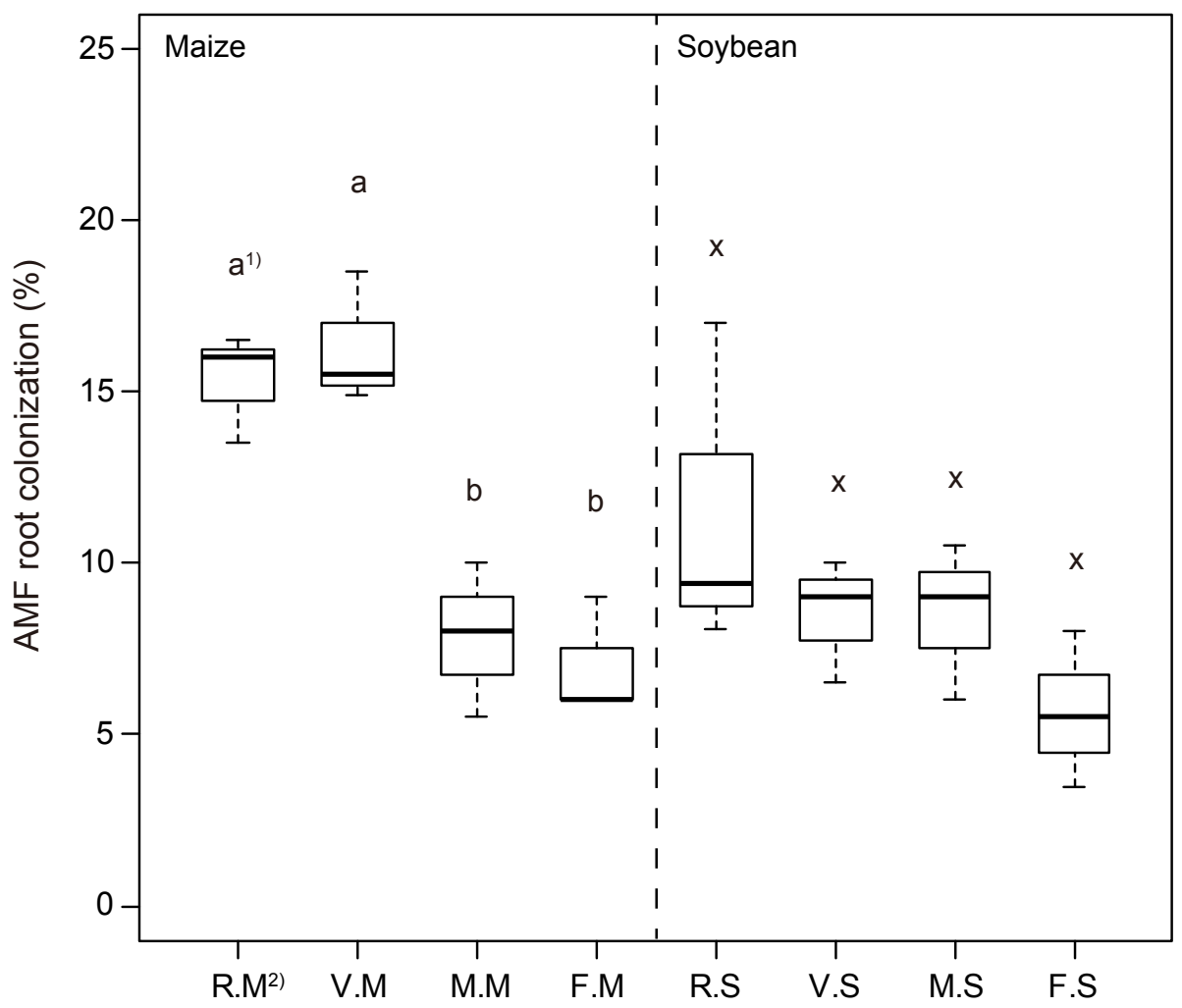




\section{Figure 2 (on next page)}

Boxplots illustrating differences in group averages in aboveground plant biomass of maize and soybean at 6 weeks after sowing.

Bold horizontal lines represent median values; box margins \pm SE and vertical lines represent minimum and maximum values of the groups. 1) Different letters in the maize or soybean plot among the cover crop treatments show a significant difference according to Tukey's test at the $5 \%$ level. 2) R.M, V.M, M.M and F.M show the aboveground plant biomass of maize after cultivation of Italian ryegrass, hairy vetch, brown mustard cropping or bare fallow, respectively. R.S, V.S, M.S and F.S show the aboveground plant biomass of soybean after cultivation of Italian ryegrass, hairy vetch, brown mustard cropping or bare fallow, respectively. $\mathrm{A}=$ Maize, $\mathrm{B}=$ Soybean. 

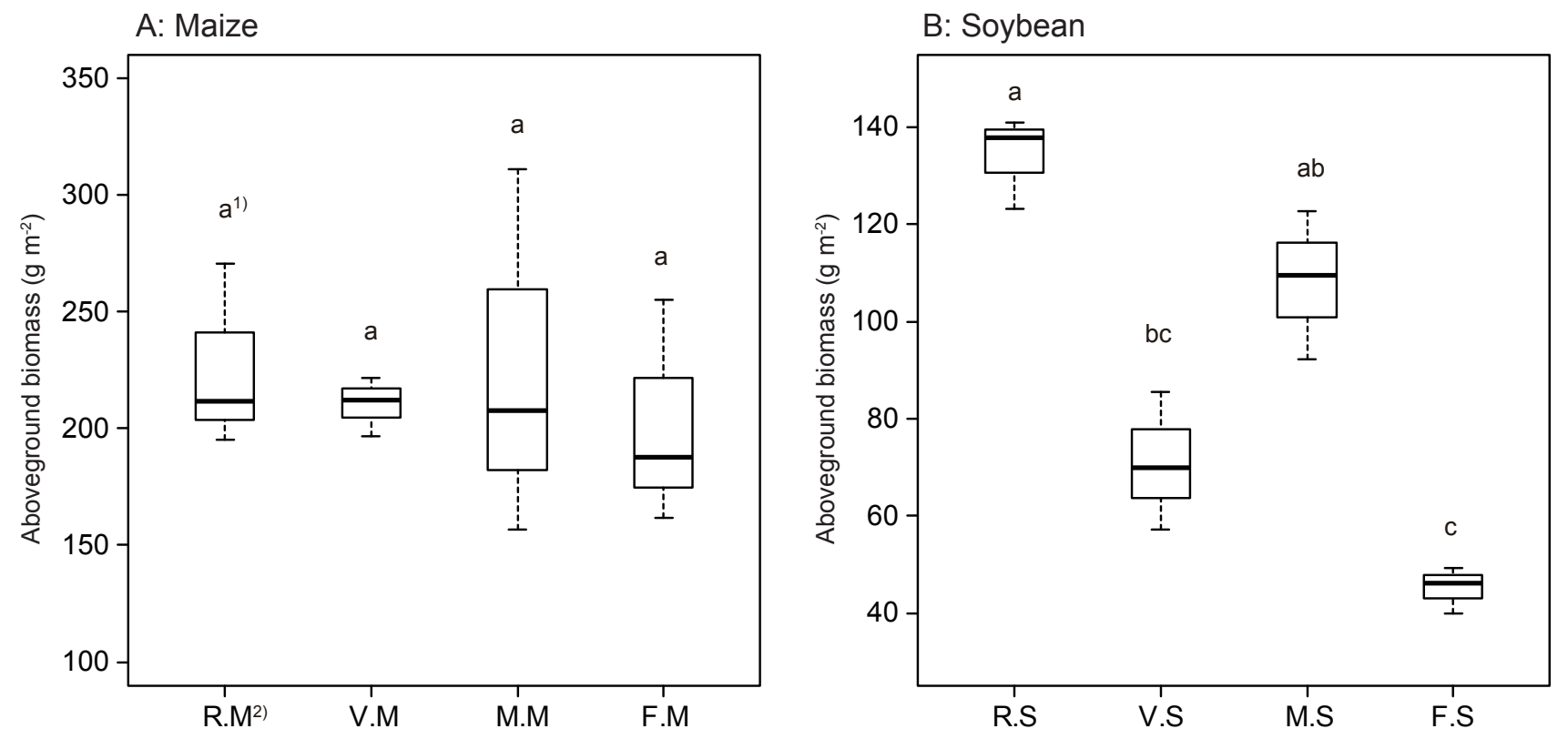
Figure 3 (on next page)

Rarefaction curves showing the amplicon sequencing depths in the maize and soybean root samples in this study.

The dashed lines show a minimum (25,116 sequences), mean (36,394 sequences) and median (36,857 sequences) number of obtained sequences in this study. The operational taxonomic units (OTUs) were compared across samples when samples were rarefied at 25,116 sequences. 


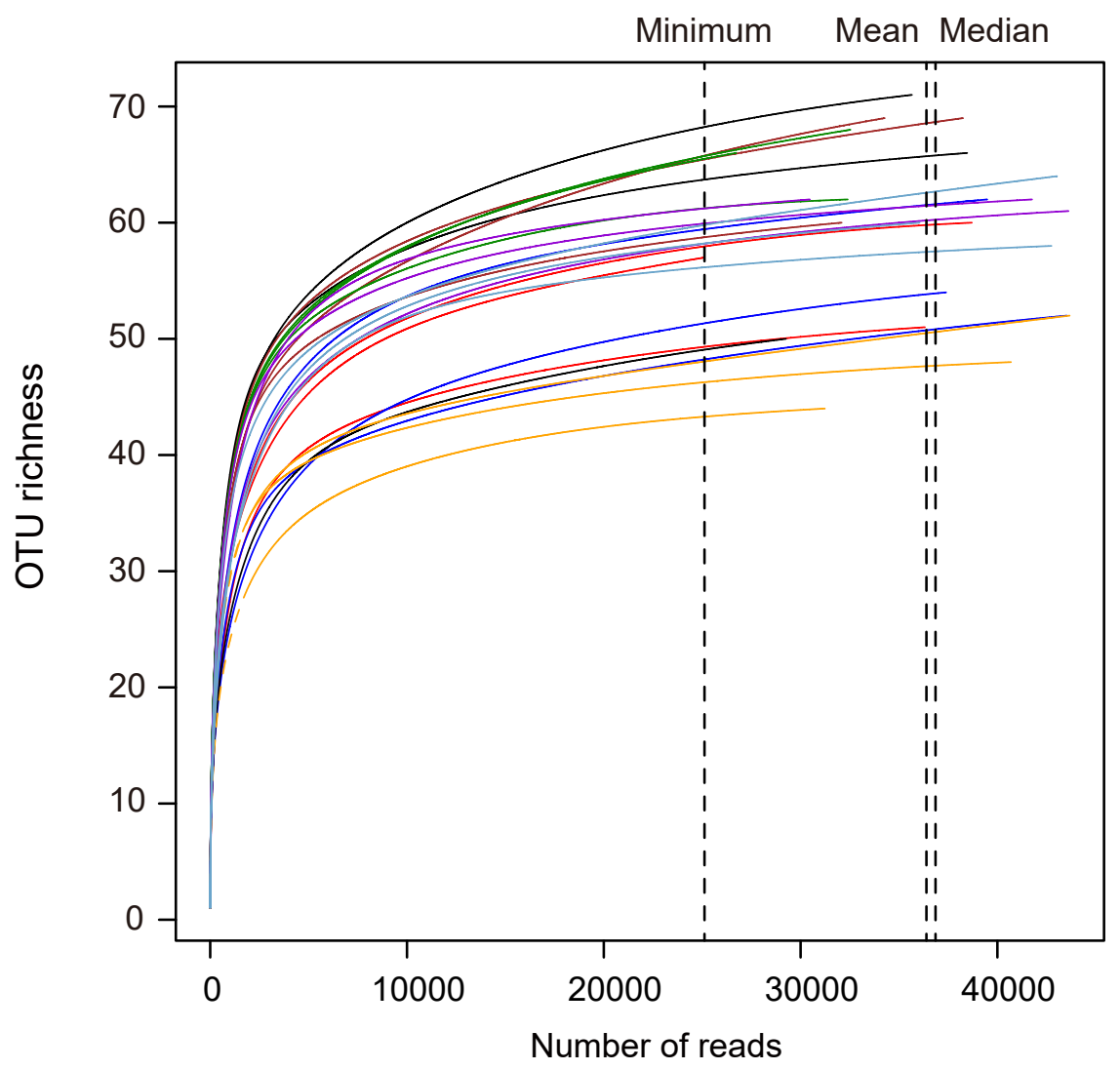




\section{Figure 4 (on next page)}

Boxplots illustrating differences in group averages regarding (A) operational taxonomic unit (OTU) richness, (B) Shannon index $\left(H^{\prime}\right)$ and $(C)$ Simpson index $(1 / D)$ in the roots of maize and soybean at 6 weeks after sowing.

Bold horizontal lines represent median values; box margins \pm SE and vertical lines represent minimum and maximum values of the groups. 1) Different letters in the maize or soybean plot among the cover crop treatments show a significant difference according to Tukey's test at the $5 \%$ level. 2) R.M, V.M, M.M and F.M show the OTU diversity of maize after Italian ryegrass, hairy vetch, brown mustard cropping or bare fallow, respectively. R.S, V.S, M.S and F.S show the OTU diversity of soybean after Italian ryegrass, hairy vetch, brown mustard cropping or bare fallow, respectively. 


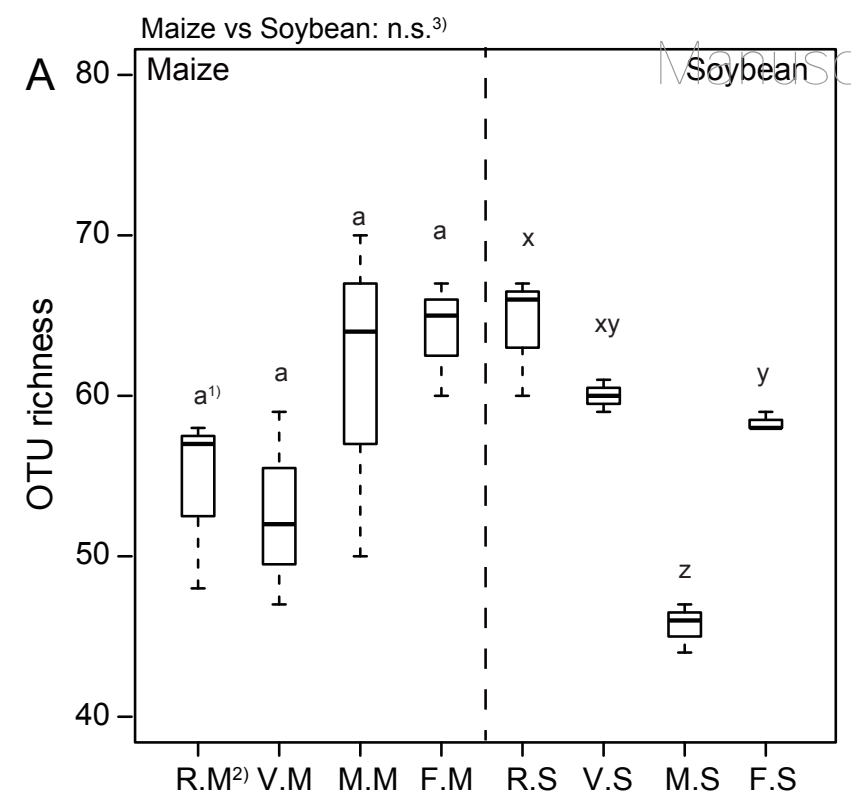

B

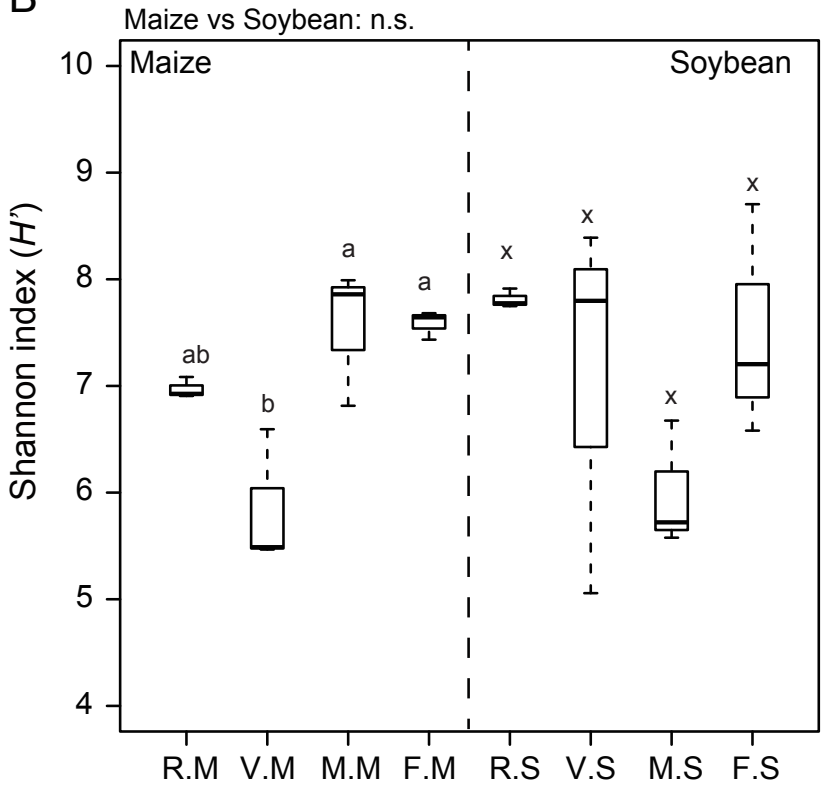

C Maize vs Soybean: n.s.

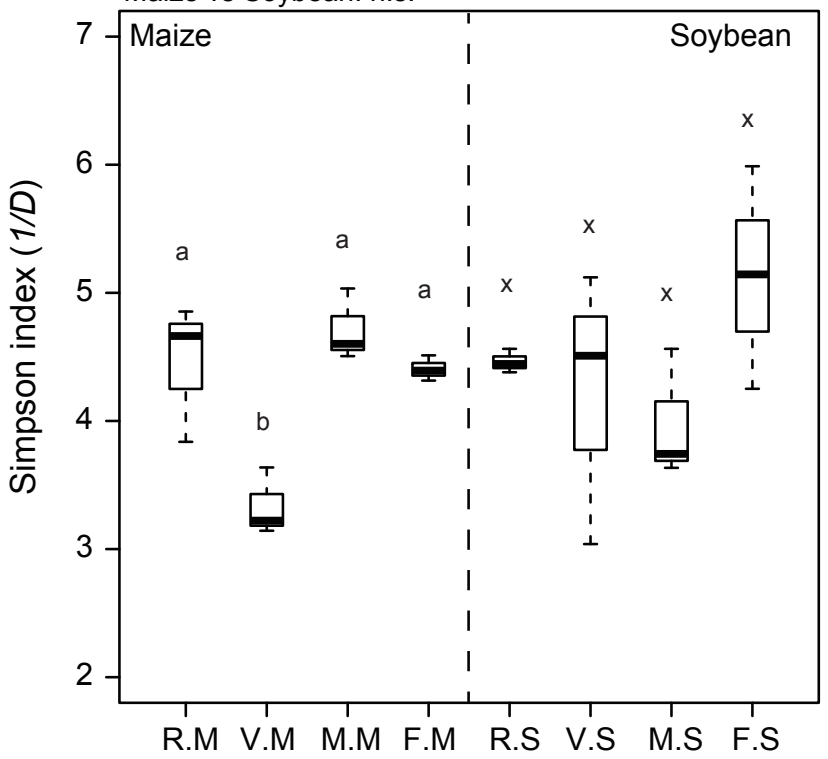




\section{Figure $\mathbf{5}$ (on next page)}

Screening of generalists and specialists of arbuscular mycorrhizal fungal communities in root samples among different cover cropping treatments.

The operational taxonomic units (OTUs) of arbuscular mycorrhizal fungi (AMF) commonly detected from both Italian ryegrass, hairy vetch or brown mustard and bare fallow treatments (circle), and those preferentially found from Italian ryegrass, hairy vetch or brown mustard (square) or bare fallow treatments (diamond). Rare AMF OTUs (triangle) were classified according to a multinomial species classification method (CLAM) test. A: Italian ryegrass versus bare fallow treatment, $B$ : hairy vetch versus bare fallow treatment, and C: brown mustard versus bare fallow treatment. 

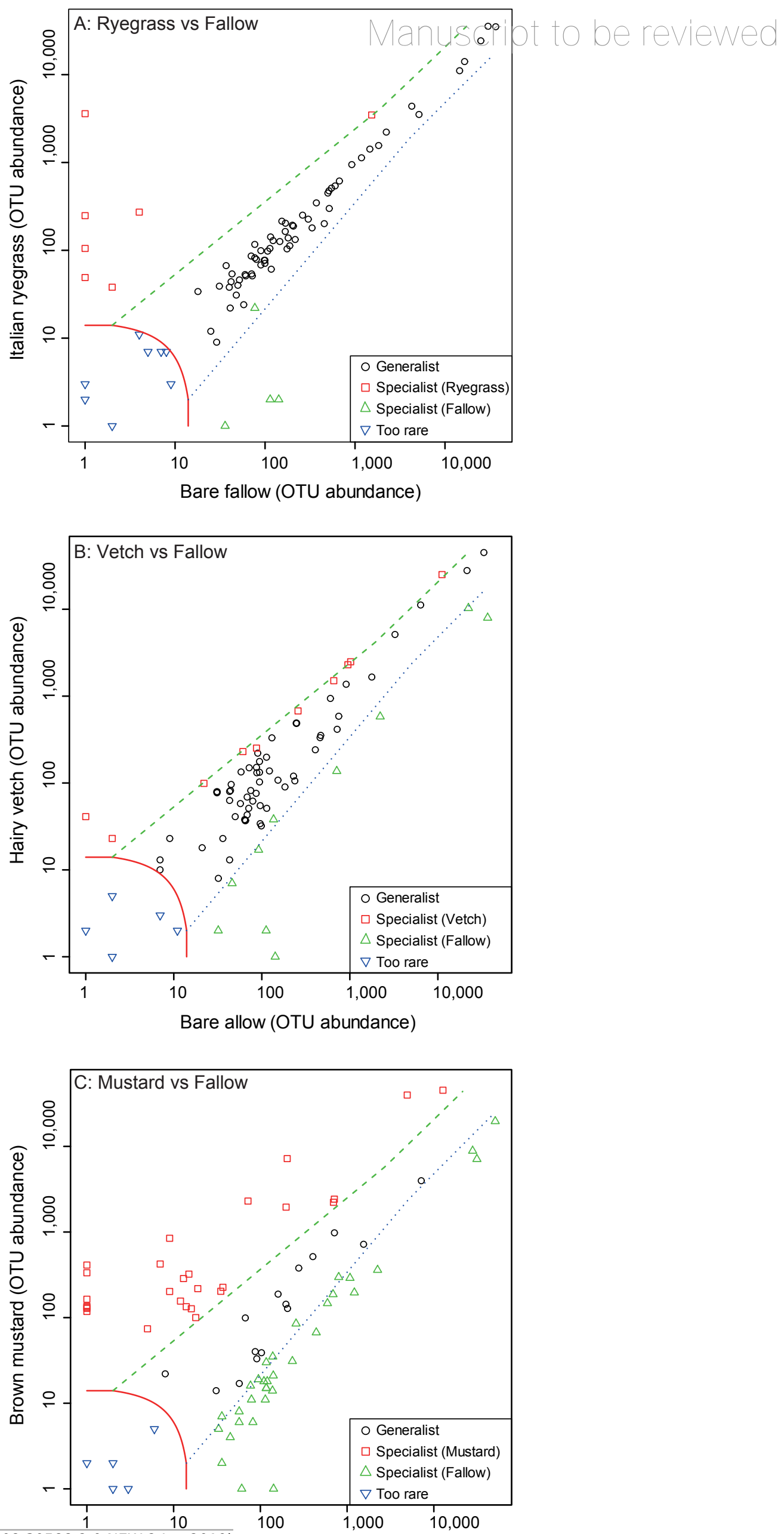
Figure 6 (on next page)

Screening of generalists and specialists of arbuscular mycorrhizal fungal communities in root samples between maize and soybean plots.

The operational taxonomic units (OTUs) of arbuscular mycorrhizal fungi (AMF) commonly detected from both maize and soybean (circle) samples; those preferentially found from maize (square) or soybean (diamond) samples were classified according to a multinomial species classification method (CLAM) test. 


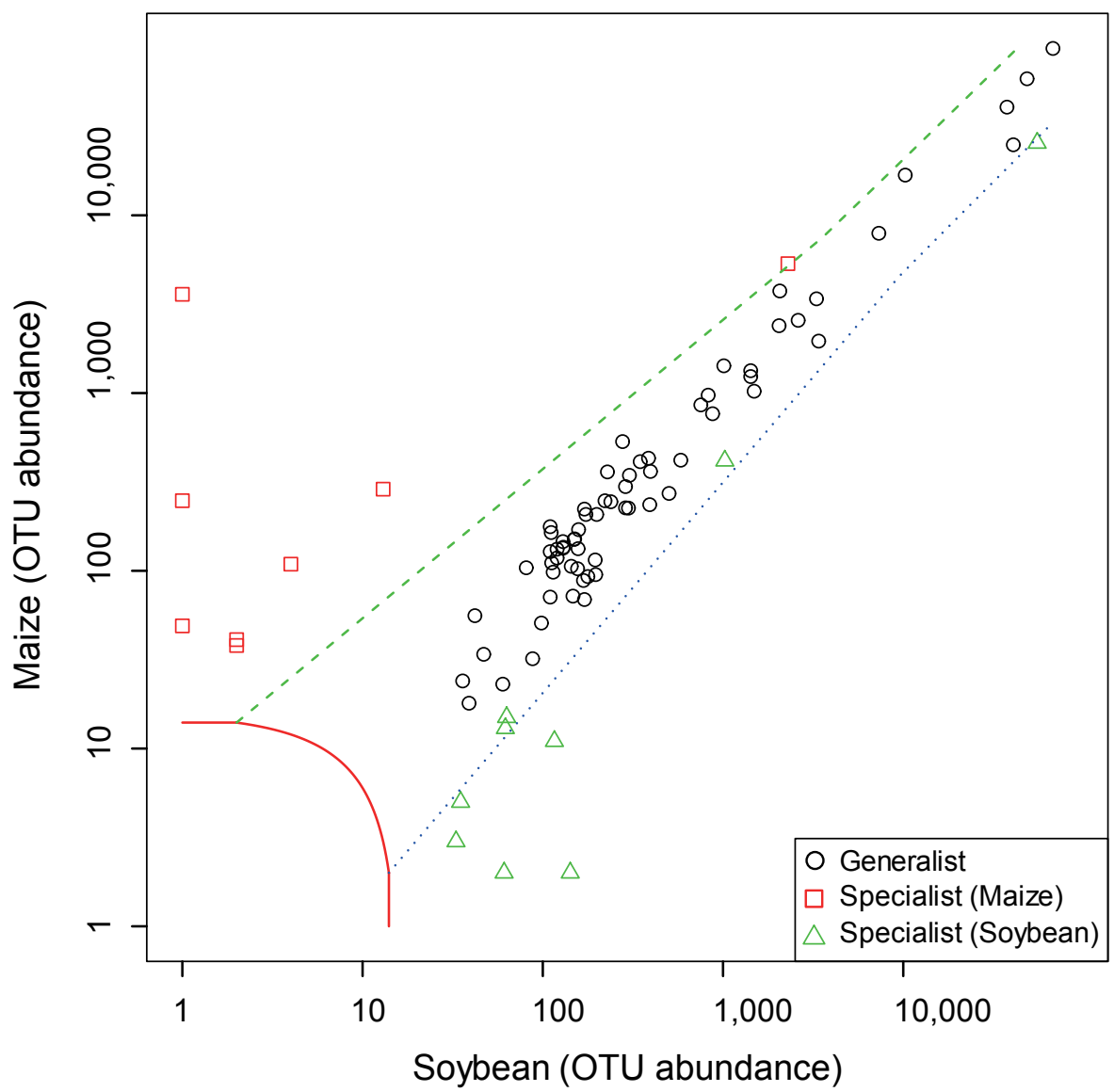




\section{Figure 7 (on next page)}

Distance-based redundancy analysis (db-RDA) biplot showing the relationship among the AMF communities and cover cropping in maize (A) and soybean (B).

Solid lines indicate significant effects, and dashed lines indicate non-significant effects. 

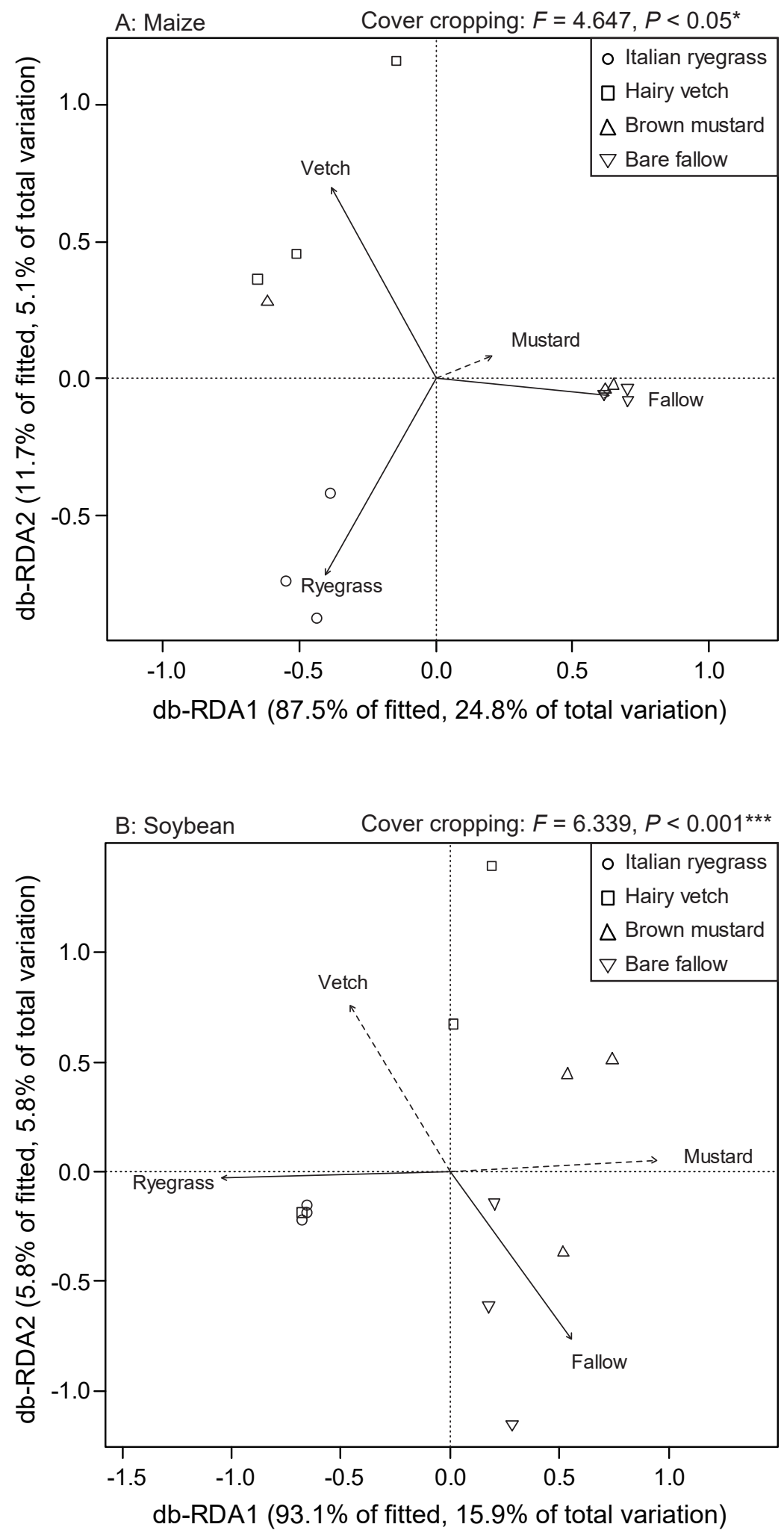


\section{Figure 8 (on next page)}

Non-metric multidimensional scaling (NMDS) plot showing differences in the arbuscular mycorrhizal fungal communities between maize (closed) and soybean (open) root samples.

Circles in the NMDS plot are 95\% confidence ellipses of maize (solid line) and soybean (dashed line). 


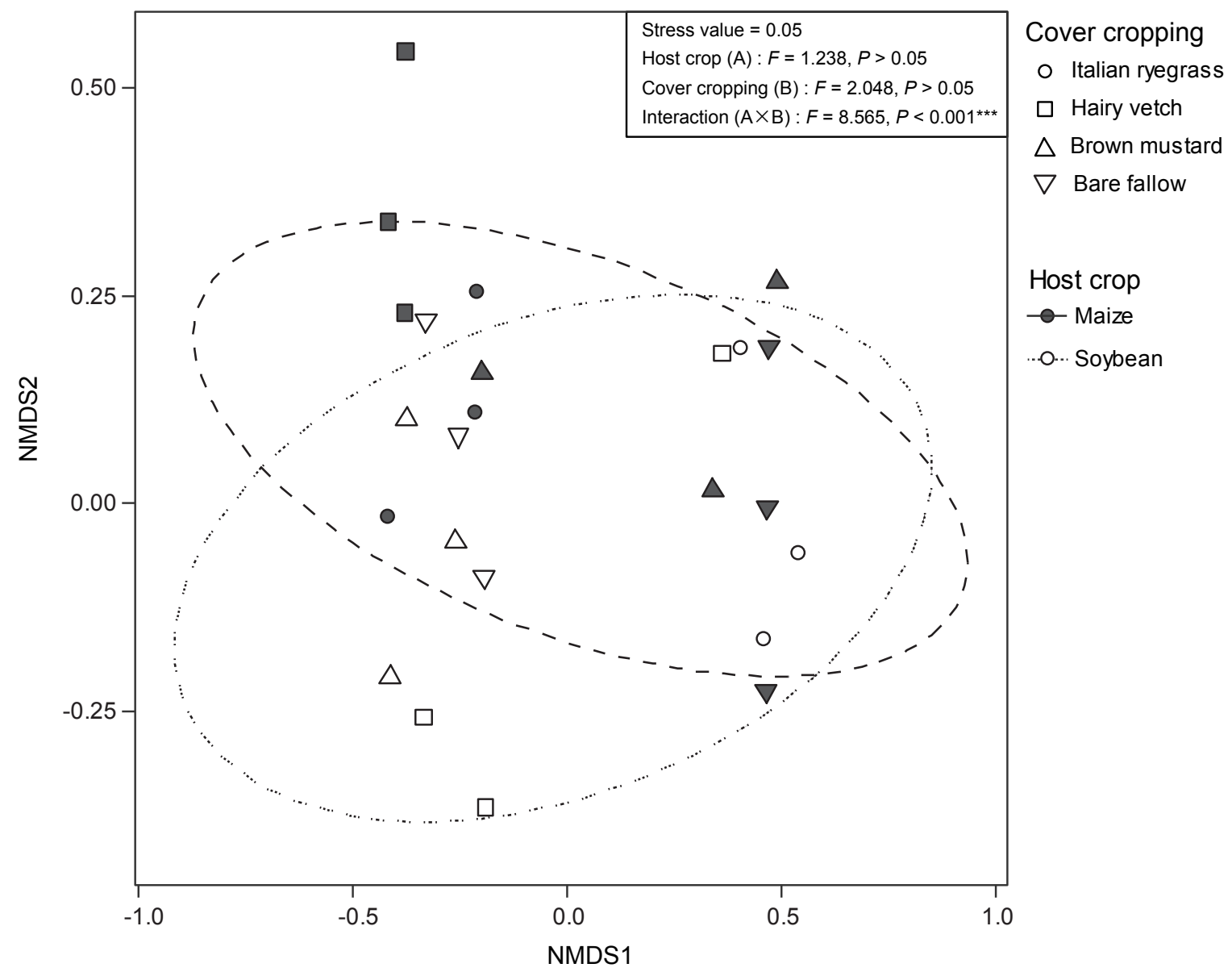

